\title{
On the Decarburization of Silicon Steel Sheet*
}

\author{
By Taketomo YAMAZAKI**
}

\section{Synopsis}

The decarburization of silicon steels at temperatures from $700^{\circ}$ to $1000^{\circ} \mathrm{C}$ in hydrogen atmosphere containing various amounts of water vapor and, in some instances, containing nitrogen has been studied.

The principal reaction in decarburization is $\mathrm{C}+\mathrm{H}_{2} \mathrm{O}=\mathrm{CO}+\mathrm{H}_{2}$. The decarburization rate increases with increasing temperature and water vapor content (dew point). At $1000^{\circ} \mathrm{C}$, the increase in the rate of decarburization by increasing the vapor pressure slowed down as it approached to $40^{\circ} \mathrm{C}$ by dew point. The rate was influenced by the behavior of the oxide films formed on the surface of steel. The effect of the equilibrium oxide films formed in the mixtures of hydrogen and water vapor on the decarburization rate was determined. Electron diffraction showed that oxide films were amorphous silica and fayalite.

The effect of oxide film on the decarburization rate depended on the crystal structure of the oxide.

\section{Introduction}

During the course of an investigation of the decarburization of commercial $3 \%$ silicon steels in the hydrogen containing water vapor and, if necessary, containing nitrogen, at temperatures from $700^{\circ}$ through $1000^{\circ} \mathrm{C}$, it was found desirable to know effects of the oxide films formed on the surface of the steel on the decarburization rate.

The oxide films were formed by oxidation of iron or alloying elements with water vapor in the atmosphere. It has been inferred that whether the oxide film is influencial or not depends not only on the properties such as crystal structure and microstructure of itself but rather intrinsically on the atmosphere composition used.

The purpose of the present work is to clarify the crystal structure and microstructure of oxide films formed in the atmosphere of low oxygen partial pressure such as a hydrogen gas with water and also the aspect of oxide formation influencing the decarburization rate.

\section{Experimental Procedure}

The experimental apparatus is schematically shown in Fig. 1. Purification of hydrogen used was done by passing the gas through DEOXO-D and zeolite. Water vapor content of the gas was controlled by passing a gas mixture preliminarily saturated with water vapor at $100^{\circ} \mathrm{C}$ through a glass tube which was installed in a thermostat automatically controlled at required temperatures, which were calculated from the published data on the vapor pressure and temperature.

A reaction tube was made of quartz. The inside of the reaction tube is illustrated in Fig. 2; there is a gas sampling hood at the middle part of the tube. The gases formed were introduced through the sampling hood into the gas burettes. The gas burettes were all connected with a glass capillary tube to a gas-chromatograph. The gas burettes were set in the nearest distance to the reaction furnace to minimize the dead space of the pipe line.

The measuring condition of gas-chromatograph is shown in Table 1. The support material mainly consisted of activated charcoal, but, when nitrogen and oxygen were intended to seperate a molecular sieve was used. For detecting $\mathrm{CO}, \mathrm{CO}_{2}, \mathrm{~N}_{2}, \mathrm{O}_{2}$, and $\mathrm{H}_{2}$

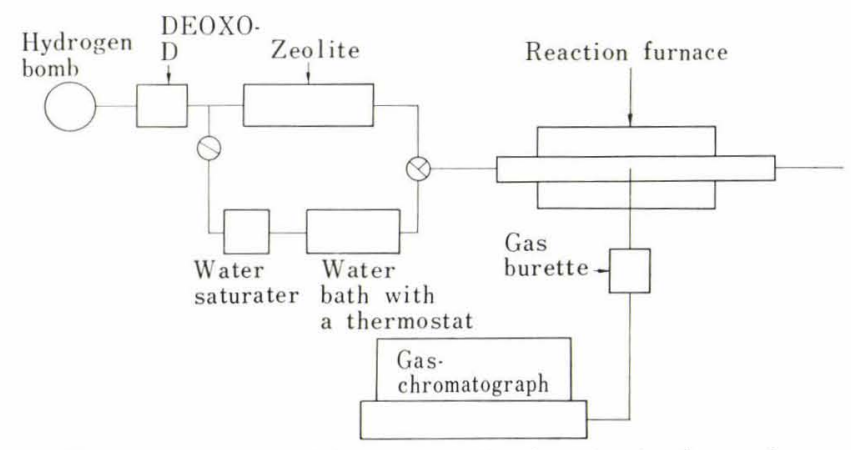

Fig. 1. Experimental apparatus for decarburization study

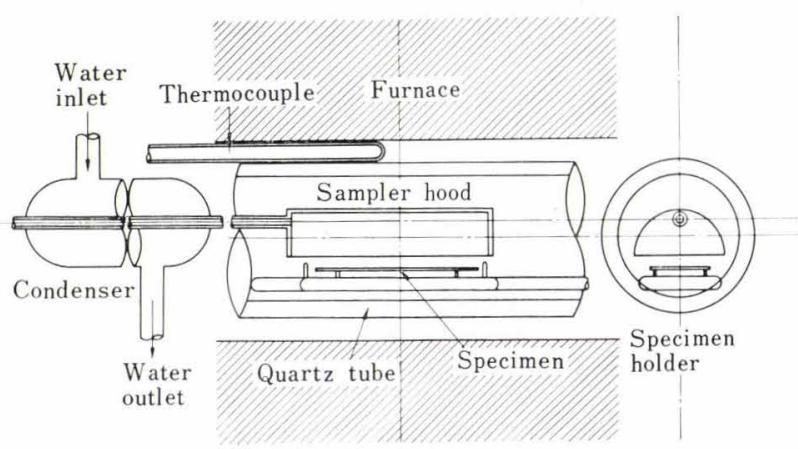

Fig. 2. Inside of the reaction tube

Table 1. Measuring condition of gas-chromatograph

\begin{tabular}{l|l}
\hline \multicolumn{1}{c|}{ Column } & \multicolumn{1}{c}{$\begin{array}{c}\text { Activated charcoal and } \\
\text { molecular sieve }\end{array}$} \\
\hline Column length & $225(\mathrm{~cm})$ \\
Column temp. & $101\left({ }^{\circ} \mathrm{C}\right)$ \\
Column material & Stainless steel \\
Detector temp. & $103\left({ }^{\circ} \mathrm{C}\right)$ \\
Bridge current & $150(\mathrm{~mA})$ \\
Carrier gas & $\mathrm{He}$ \\
Pressure & $0.4\left(\mathrm{~kg} / \mathrm{cm}^{2}\right)$ \\
Flow rate & $90(\mathrm{cc} / \mathrm{min})$ \\
\hline
\end{tabular}

* Presented at the Joint Symposium of U.S.S.R. and Japan on Physical Chemistry of Metallurgical Processes, May, 1967 in Moscow. Manuscript received July 29, 1968.

** Central Research Laboratories, Fuji Iron \& Steel Co., Ltd., Fuchinobe, Sagamihara 229. 
the thermal conductivity method was used. However, for $\mathrm{CH}_{4}$ or other organic gases, the hydrogen ionization method was used which is capable of detecting a few ppm of $\mathrm{CH}_{4}$ and organic gases.

Gas flow rates were from 100 to $500 \mathrm{cc} / \mathrm{min}$ and, if necessary, 1000 , to $2000 \mathrm{cc} / \mathrm{min}$. Gas pressure was about 760 torr. Most of the experiments were conducted at $700^{\circ}, 800^{\circ}, 900^{\circ}$, and $1000^{\circ} \mathrm{C}$. Specimens of silicon steels were held for various durations preselected, the longest one being three hours. Gaschromatography was used at regular intervals for analyses of gases produced after successive reactions between the specimen and the atmosphere.

The cycle of measurement was limited depending on the gas measured; for instance, $\mathrm{CO}$ requires four minutes of retention time under this measuring condition.

Three percent silicon steel was used as the specimens. The specimens were cut in $20 \times 50 \times 1 \mathrm{~mm}$ and annealed at $950^{\circ} \mathrm{C}$ for three hours in vacuum of $3 \times 10^{-4}$ torr. Before heat treatment, each specimen was polished to $0 / 3$ emery paper, cleaned and dried using benzene, acetone, absolute alcohol, and ether.

General procedure of the experiment was as follows: when the furnace, in which nitrogen was flowing, was at the desired temperature, the predetermined gas mixture was passed through the furnace and the specimen was moved toward the center of quartz tube by means of a specimen holder, the cool-end of which was attached to a magnet. After heat treatment, specimens were moved back to a cool part, and the atmospheres were immediately purged from the furnace with a stream of hydrogen and then nitrogen.

During heat treatment, water content of the mixtures was carefully checked by means of a hydrometer. Start of measuring time was taken at the time when the specimen reached at the center of the tube. Actually, the temperature of the furnace was slightly lowered, but recovering time did not exceed about one minute, which was checked by measuring temperature drop with a thermocouple directly brazed at the specimen or pressure drop of the atmosphere of the furnace tube.

Measurement of the gases by gas-chromatograph was made each minute up to five minutes and, after that period, at 10, 15, 30, 60, and 180 minutes. Volume of each burette is $1 \mathrm{cc}$.

\section{Experimental Results}

\section{Formation of $\mathrm{CO}$ and $\mathrm{CH}_{4}$ during Heat Treatment}

The gases detected were only $\mathrm{CO}$ and $\mathrm{CH}_{4}$, although $\mathrm{CO}_{2}$ was expected to appear.

The variation of the amounts of $\mathrm{CO}$ and $\mathrm{CH}_{4}$ as a function of time was measured under the condition in which water content, temperature, and flow rate were kept constant. Figures 3 and 4 show the curves obtained at $800^{\circ}$ and $1000^{\circ} \mathrm{C}$. The formation of $\mathrm{CH}_{4}$ was considerably small and deservedly less than that of CO.

For $\mathrm{CO}$, it was recognized that at temperatures lower than $800^{\circ} \mathrm{C}$ the amount of $\mathrm{CO}$ after the maximum point of the curve lowered monotonously. On the other hand, specimens heated at temperatures higher than $900^{\circ} \mathrm{C}$ gave complicated curves. The curve obtained for the specimens heated at $1000^{\circ} \mathrm{C}$ shows the second maximum point at about $20 \mathrm{~min}$ of time as shown in Fig. 4. This tendency was more marked at $1000^{\circ} \mathrm{C}$ than at $900^{\circ} \mathrm{C}$.

The formation of $\mathrm{CH}_{4}$ is exceedingly small. Moreover, all the curves are qualitatively similar to one another and the second maximum point does not appear, even if temperatures are higher than $900^{\circ} \mathrm{C}$.

Figure 5 shows the variation of the total amount of $\mathrm{CO}$ and $\mathrm{CH}_{4}$ as a function of time under the condition in which treating temperature is $1000^{\circ} \mathrm{C}$, dew point $30^{\circ} \mathrm{C}$, and flow rate $150 \mathrm{cc} / \mathrm{min}$, respectively. The ordinate of the figure is the total of partial pressures of $\mathrm{CO}$ and $\mathrm{CH}_{4}$, so that the product of the total amount of $\mathrm{CO}$ and $\mathrm{CH}_{4}$ partial pressures and the flow rate is the actual amount of $\mathrm{CO}$ plus $\mathrm{CH}_{4}$ liberated from the specimen at the time of the measurement.

Accordingly, the decarburization degree at the time $t$ will be expressed as a ratio of the carbon content $\left(\mathbf{C}_{f}\right)$ calculated for the total amount of $\mathrm{CO}$ and $\mathrm{CH}_{4}$ liberated till the time $t$ - that is the area surrounded by the curve of $\mathrm{CO}$ plus $\mathrm{CH}_{4}$ and the vertical axes at 0 and $t$

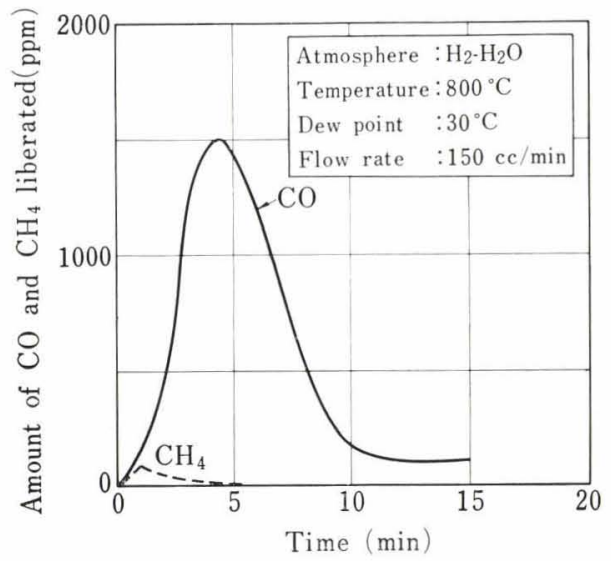

Fig. 3. Relation between amount of $\mathrm{CO}$ and $\mathrm{CH}_{4}$ and time obtained for specimen heated at $800^{\circ} \mathrm{C}$ in atmosphere with water vapor content of $30^{\circ} \mathrm{C}$

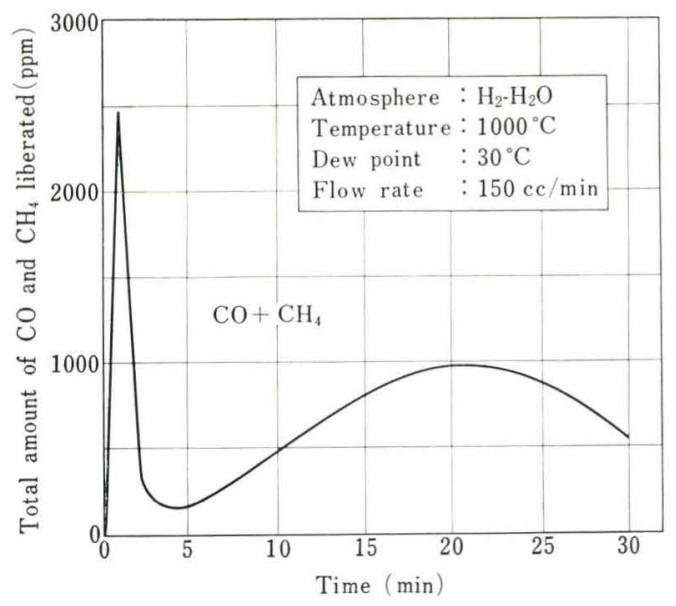

Fig. 4. Relation between amount of $\mathrm{CO}$ and $\mathrm{CH}_{4}$ and time obtained for specimen heated at $1000^{\circ} \mathrm{C}$ in atmosphere with water vapor content of $30^{\circ} \mathrm{C}$ 
of the abscissa - to the initial carbon content $\left(\mathrm{C}_{0}\right)$ of the steel.

Here, the decarburization degree is expressed as $(1-a)$, here $a=\mathrm{C}_{f} / \mathrm{C}_{0}$.

The relationship between $(1-\alpha)$ and time is shown in Fig. 6. The points indicated by small open circles in the figure are the decarburization degrees $(1-\alpha)$ obtained from the values by chemical analyses of specimens heated for 4, 30, and $60 \mathrm{~min}$, respectively. Their values are quite consistent with the line by the gas analyses within experimental error. From the figure, it can be seen that the decarburization proceeds very slowly for the first ten minutes and, after that period, very rapidly approaching to the lowest level. This gradual transition in the decarburization degree results from the process that the second formation of $\mathrm{CO}$ occurs increasingly to the maximum.

\section{Effect of Treating Temperature and Water Content on Decarburization Rate}

Effects of the water content in the mixture on the decarburization rate are shown in Figs. 7 and 8 .

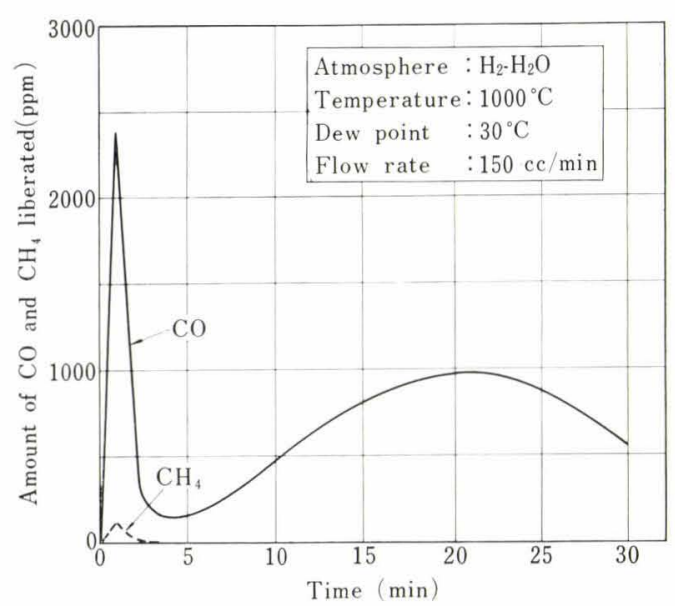

Fig. 5. Relation between total amount of $\mathrm{CO}$ and $\mathrm{CH}_{4}$ and time obtained for specimen heated at $1000^{\circ} \mathrm{C}$ in atmosphere with water vapor content of $30^{\circ} \mathrm{C}$

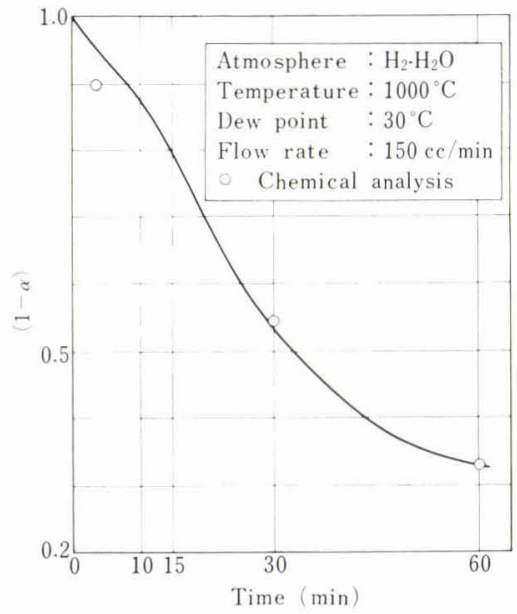

Fig. 6. Relation between $1-\alpha$ and time obtained for specimen heated at $1000^{\circ} \mathrm{C}$ in atmosphere with water vapor content of $30^{\circ} \mathrm{C}$
Figure 7 shows the effect of water vapor content on the decarburization rate for the specimens heated at $800^{\circ} \mathrm{C}$, showing an increase in the decarburization rate with increasing water vapor content. From Fig. 8, on the other hand, the decarburization rates at $1000^{\circ} \mathrm{C}$ with dew points of $0^{\circ}$ and $10^{\circ} \mathrm{C}$ were lower than those at $800^{\circ} \mathrm{C}$. With dew points of $20^{\circ}$ to $40^{\circ} \mathrm{C}$, however, the rates were greater than those at $800^{\circ} \mathrm{C}$. And, it is also seen that the decarburization of specimens heated in the mixtures with water vapor content of $40^{\circ} \mathrm{C}$ in dew point is somewhat smaller than that of $30^{\circ} \mathrm{C}$. Thus, it is understood that when the water vapor content at $1000^{\circ} \mathrm{C}$ exceeds a definite value, the decarburization rate rather decreases.

\section{Identification of Crystal Structure of Oxide Film Formed on Surface of Steel by Means of Electron Diffraction}

For the specimens heated at higher temperatures, marked effects of the dew point on the decarburization rate were recognized.

So, in order to clarify the relation between the decarburization rate and the structure of the oxide film

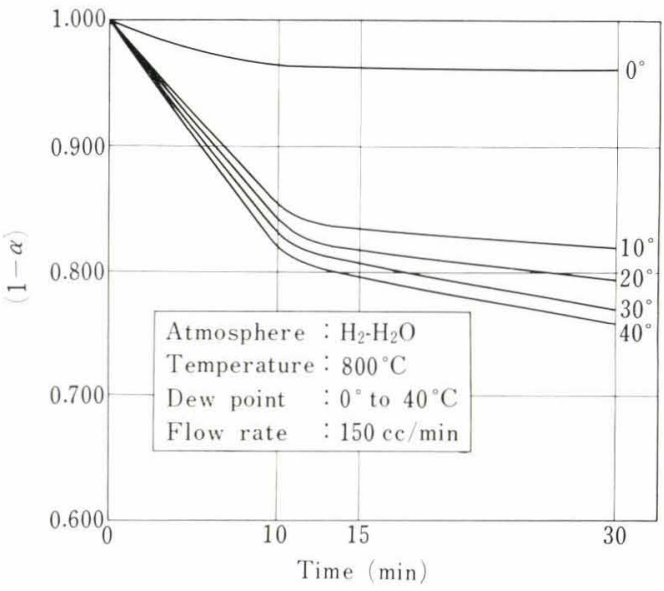

Fig. 7. Relation between $1-\alpha$ and time

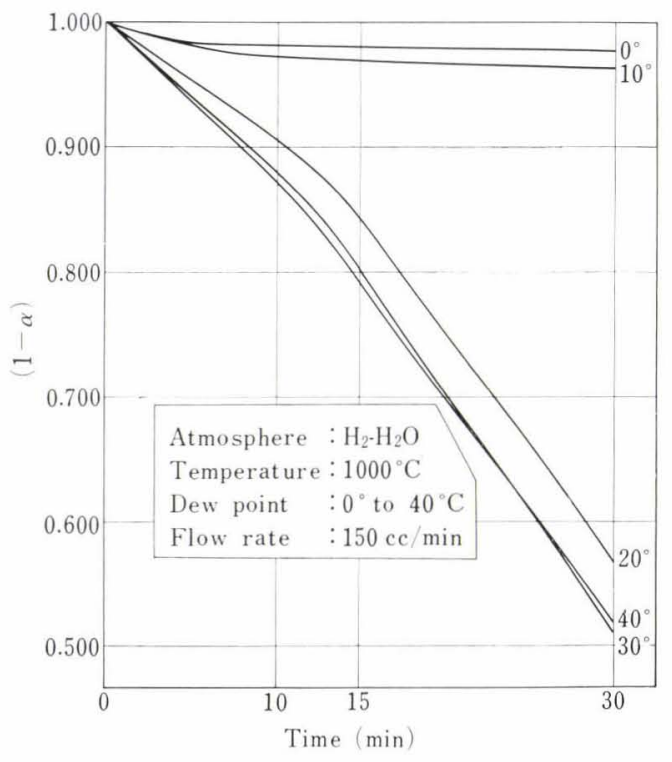

Fig. 8. Relation between $1-\alpha$ and time 
which is considered to change depending on the water vapor content and temperature, identification of the crystal structure of the oxide films formed on the surface of steel heated at $1000^{\circ} \mathrm{C}$ up to three hours was made by means of electron diffraction.

Most of the electron diffraction patterns were obtained by transmission of the oxide films which were stripped from the surface by immersing the specimen in a 1 or $3 \%$ bromine methanol solution.

But, in some cases, the patterns were obtained by glancing angle reflection. Most of the stripped films yielded satisfactory transmission patterns. Both of the diffraction methods showed the same result. The results are summarized in Table 2, showing also the process of the oxide film formation. From the table, the effect of water vapor content on the oxide formation and growth was recognized. The oxide formation becomes fast as the water vapor content increases. Even in the period as short as two minutes, the oxide film was promptly observed. The patterns for specimens heated at $1000^{\circ} \mathrm{C}$ showed amorphous, $\alpha$ (low) cristobalite, and rarely $\alpha$ (low) quartz with co-existing $\alpha$-cristobalite. Apart from the initial period in which the oxide film consisted mainly of amorphous silica, the oxide film of amorphous silica was crystallized to cristobalite and rarely tridymite. Also this crystallization of amorphous silica to cristobalite was much more accelerated with increasing water vapor content.

In the mixture with the water vapor content of dew point $60^{\circ} \mathrm{C}$, the formation of fayalite was recognized instead of the formation of silica.

Table 3 shows an example of identification results, showing that the formation of tridymite was found even in the mixture with the water vapor content of dew point $-49^{\circ} \mathrm{C}$. This result is in accord with that of A.U. Seybolt. ${ }^{1)}$ Therefore, silicon steel can be easily oxidized at low dew point such as $-49^{\circ} \mathrm{C}$. But, slowness in the growth rate of the oxide film formed at lower dew points can be deduced from Table 2.

\section{Electron Microscopy and Electron Microprobe Analysis}

The electron microstructures of the oxide films formed at earlier stages are shown in Photo. 1. Photographs were taken by direct observation technique for the stripped films. Photographs (a) and (b) are the electron microstructures of amorphous silica and of fayalite, respectively. Although the treating time is only three minutes, both of the films grow sufficiently and uniformly. After a long period of heating, the oxide film does not necessarily grow uniformly, but does irregularly. Accordingly, the appearance of oxide film became considerably uneven. Photograph 2 (p. 71) shows, from (a) to (d), how the electron microstructures of specimens which were heated at $1000^{\circ} \mathrm{C}$ in a $\mathrm{H}_{2}$ gas with water vapor of $30^{\circ} \mathrm{C}$ dew point change with time of heating.

They are of amorphous silica in crystal structure. Photograph 2 (a) (4 min) is similar to Photo. 1 (a), showing relatively uniform structure. In Photograph 2 (c) $(15 \mathrm{~min})$, the structure has already become uneven, this tendency becoming more remarkable with increasing time.

It is likely that the reason for this uneven structure is characteristic of silicon steels heated in a mixture of hydrogen and water vapor. Since silicon is much more capable of combining with oxygen than iron, oxygen will react with silicon to form silica at suitable sites for nucleation.

Table 2. Results of electron diffraction and the brightness of specimen surface

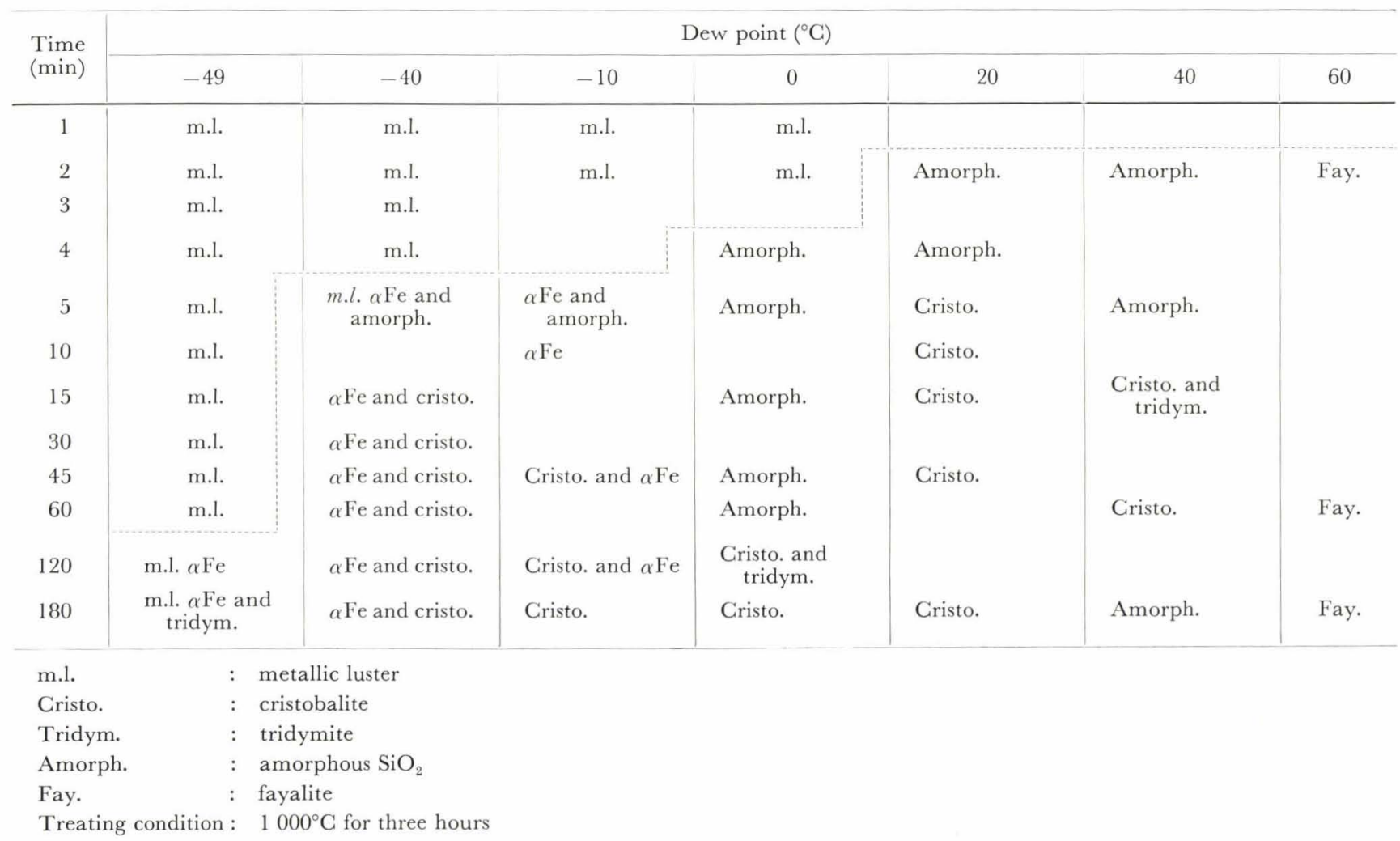


Table 3. Electron diffraction results

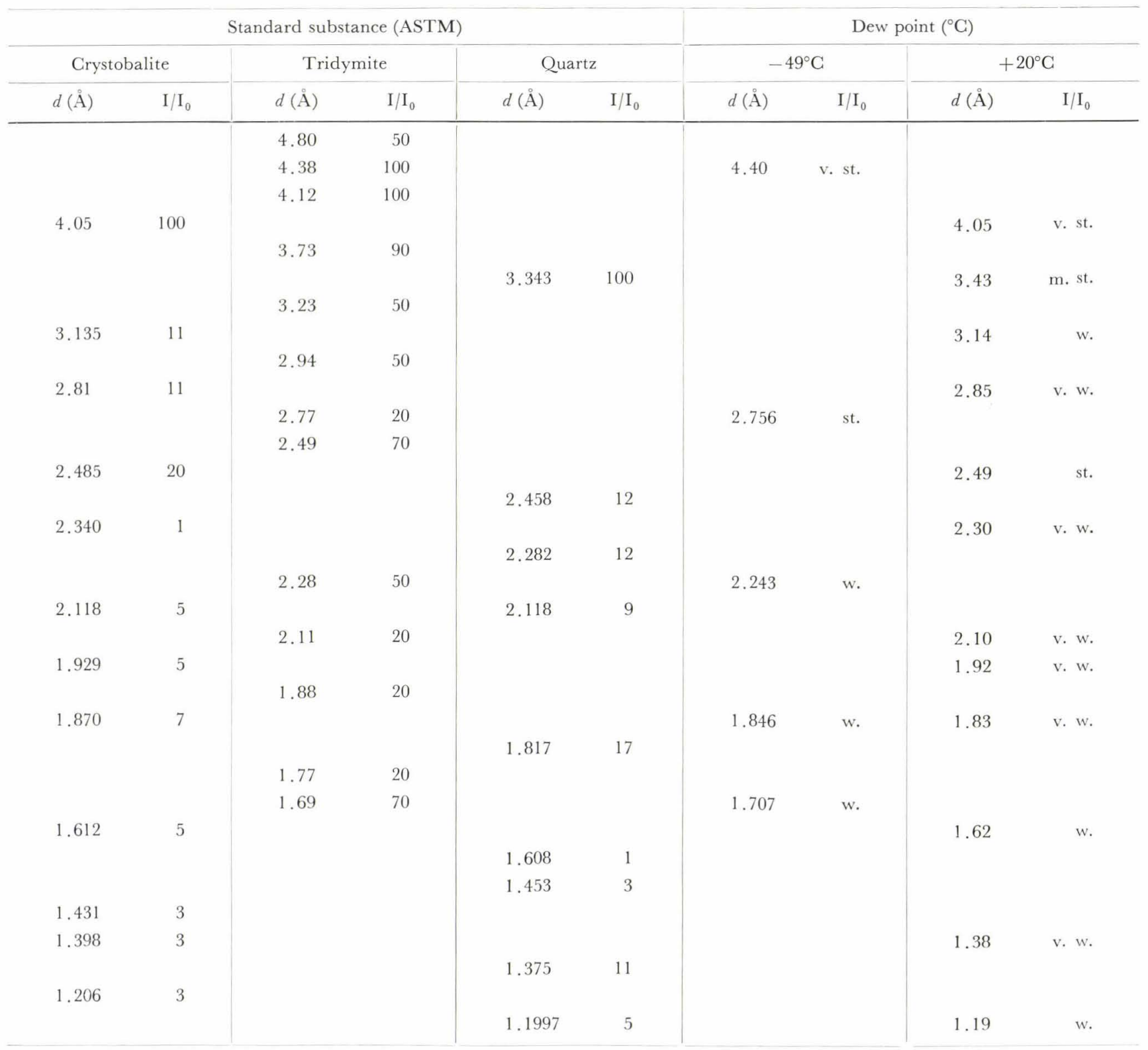

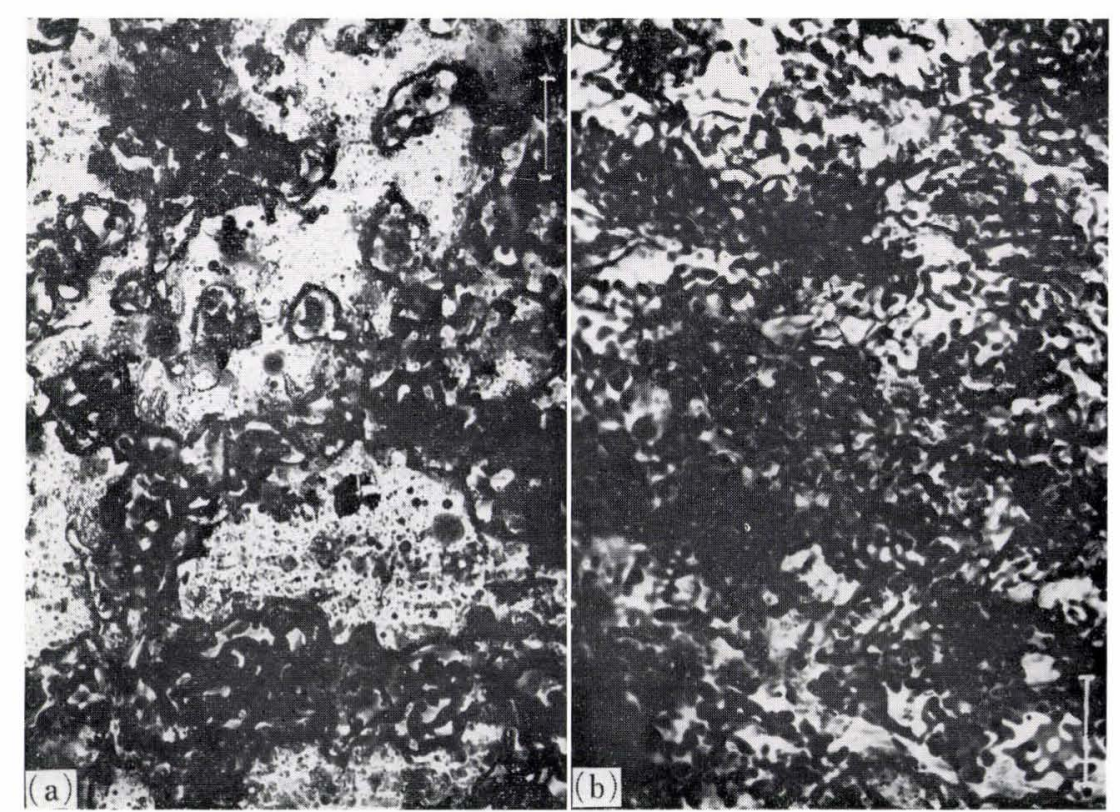

Photo. 1. Electron microstructure

(a) Temperature: $950^{\circ} \mathrm{C}$ Time : $3 \mathrm{~min}$ $\mathrm{H}_{2} \mathrm{O} / \mathrm{H}_{2} \quad: \quad 0.024$ Showing amorphous $\mathrm{SiO}_{2} \quad(\times 5000)(2 / 3)$

(b) Temperature: $950^{\circ} \mathrm{C}$ Time : $3 \mathrm{~min}$ $\mathrm{H}_{2} \mathrm{O} / \mathrm{H}_{2} \quad$ : 0.262 Showing fayalite $(\times 5000)(2 / 3)$ 
As the reaction proceeds, the silica layer increases in both thickness and extent. When the silica film covers a whole surface of the specimen and further grows, the coaguration will occur and consequentiy it will cause a fault considered to be a path of iron ion and water vapor.

As mentioned above, it is likely that since this oxide film is of amorphous silica, it never contains iron oxide. In order to ascertain this aspect semiquantitative analysis was made by Hitachi-HXA in which an electron microprobe analyser is built, which is capable of measuring heavier elements than $\mathrm{Mg}$ (atomic number 12 ) in the electron microscopic field of vision.

For quantitative analysis by EPMA, as already known, the region of specimen to be analyzed must be thick enough to stop all the incident electrons. Otherwise, the X-ray intensity generated will be less by the fraction of electrons that passes through and the calibration curves must be made by taking account of the thickness as well as the composition. In order to obtain the exact value of composition, the thickness of film to be analyzed must be preliminarily measured. But, it is impossible, especially for the uneven film.

Hence, determination of the contents of iron and silicon in the film by EPMA was made only in the selected place where the specimen current appeared the same, so that the value had to be left just as obtained in count per second. The results thus obtained are shown in Table 4 . No. 3 in the table is the results thus obtained for the specimens the structure of which is amorphous silica. Specimen current is $0.6 \times 10^{-8} \mathrm{~mA}$ for thick part and $0.3 \times 10^{-8} \mathrm{~mA}$ for thin part of the film, respectively. The value for the thick part of film is almost two times that of the thin part. However, the counting values for both of the parts are almost same. Then, it is evident that although most of the film consists of amorphous silica, a slight amount of iron is contained. For No. 8, the film consists of fayalite and differs in the contents of iron and silicon in thick and thin parts of the film. The silicon content relative to the iron content in the thick part of film is low, but high in the thin part. Accordingly,
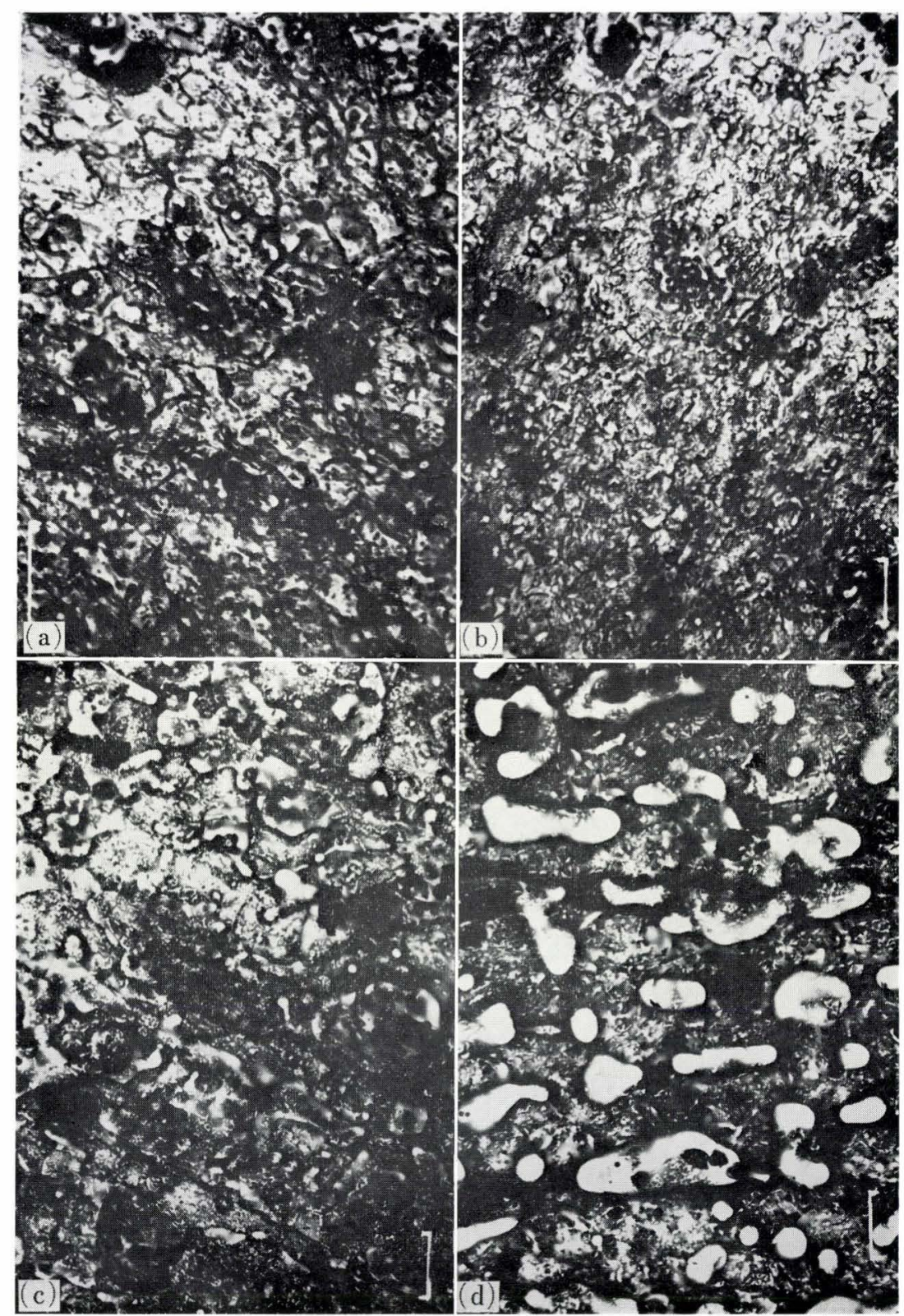

Photo. 2. Electron microstructure showing structural change during heating $(\times 5000)(2 / 3)$
(a) $4 \mathrm{~min}$
(b) $6 \mathrm{~min}$
(c) $15 \mathrm{~min}$
(d) $60 \mathrm{~min}$ 
Table 4. Si and Fe detection by EPMA built in an electron microscope (HXA)

\begin{tabular}{|c|c|c|c|c|c|}
\hline \multirow{2}{*}{ Specimen No. } & \multicolumn{2}{|l|}{8} & 4 & \multicolumn{2}{|l|}{3} \\
\hline & $\mathrm{Si}$ & $\mathrm{Fe}$ & $\mathrm{Fe}$ & $\mathrm{Si}$ & $\mathrm{Fe}$ \\
\hline & \multicolumn{5}{|c|}{ Counts per second } \\
\hline Thick part & \multicolumn{2}{|c|}{$\left(0.5 \times 10^{-8} \mathrm{~mA}\right)^{30}$} & ${ }_{\left(0.5 \times 10^{-8} \mathrm{~mA}\right)}^{23}$ & \multicolumn{2}{|l|}{${ }_{\left(0.6 \times 10^{-8} \mathrm{~mA}\right)}^{8}$} \\
\hline Thin part & \multicolumn{2}{|c|}{$\left(0.3 \times 10^{-8} \mathrm{~mA}\right)$} & $\left(0.2 \times 10^{-8} \mathrm{~mA}\right)^{23}$ & $\stackrel{94}{\left(0.3 \times 10^{-8} \mathrm{~mA}\right)}$ & 4 \\
\hline Crystal structure & \multicolumn{2}{|l|}{ Fayalite } & $\begin{array}{l}\text { Amorphous } \mathrm{SiO}_{2} \text { and } \\
\text { fayalite }\end{array}$ & \multicolumn{2}{|l|}{ Amorphous $\mathrm{SiO}_{2}$} \\
\hline Temperature $\left({ }^{\circ} \mathrm{C}\right)$ & \multirow{2}{*}{\multicolumn{2}{|c|}{$\begin{array}{l}950 \\
\quad 0.26\end{array}$}} & \multirow{2}{*}{$\begin{array}{r}850 \\
0.26\end{array}$} & \multicolumn{2}{|l|}{850} \\
\hline$p_{\mathrm{H}_{2} \mathrm{O}} / p_{\mathrm{H}_{2}}$ & & & & 0.078 & \\
\hline
\end{tabular}

it is concluded together from the electron microscopic observation (Photo. 1 (a)) that the thin part of film must consist of amorphous silica. This fact shows that silica forms first and then probably fayalite forms by a solid state reaction of silica with iron oxide.

C. W. Tuck ${ }^{2)}$ has discussed the formation of fayalite on the surface of silicon steel in water vapor or carbon dioxide atmosphere. According to his discussion, when an unoxidized surface of silicon steel is brought into contact with oxygen at a temperature high enough for reaction to take place, two separate processes will occur. As previously mentioned, silicon first reacts with oxygen to form silica, at the same time, iron will also react with the oxide ions adsorbed on the surface; the reaction process is accelerated by the layer denuded of silicon by selective oxidation of silicon. In so reacting, the iron will form the iron oxide or oxides outside the silica. Hence, the reaction between wustite and silica to form fayalite can occur simultaneously if wustite is thermodynamically stable in equilibrium with the mixture with a suitable oxygen partial pressure.

Finally, for No. 4 in Table 4, the structure of film consists of fayalite in co-existence with silica. The silicon content is rich for both of the thick and thin parts of film. Comparing with the film consisting of silica only, the iron content is slightly abundant for both parts.

Summarizing these facts and discussing a change of the structure and composition of film depending on water vapor content, the formation mechanism of silica and fayalite follows the process proposed by C.W. Tuck.

Deducing from the results mentioned above it is concluded that the hydrogen gas with water vapor in the range of $\mathrm{H}_{2} \mathrm{O} / \mathrm{H}_{2}$ used here has a low oxygen partial pressure which is capable of forming wustite only, and therefore that fayalite formation occurs.

\section{Relation between Structure of Oxide Film and Oxygen Partial Pressure}

It is convenient to use the pressure ratio of $\mathrm{H}_{2} \mathrm{O} / \mathrm{H}_{2}$ in the gas phase rather than the pressure in terms of the partial pressure of oxygen; it is obvious that these are interchangeable by means of the equilibrium constant for the homogeneous gas reaction,

$$
\begin{array}{r}
\mathrm{H}_{2}+\frac{1}{2} \mathrm{O}_{2}=\mathrm{H}_{2} \mathrm{O} \ldots \ldots \ldots \ldots \ldots \ldots \\
\ln P_{\mathrm{O}_{2}}=\Delta G^{\circ} / R T+2 \ln \left(P_{\mathrm{H}_{2} \mathrm{O}} / P_{\mathrm{H}_{2}}\right) .
\end{array}
$$

Table 5 shows the relation between the structure of the film (observed by means of electron diffraction) and the pressure ratio of $\mathrm{H}_{2} \mathrm{O} / \mathrm{H}_{2}$. It is evident that the condition to form the amorphous silica, fayalite, or intermediate of these structures depends on the pressure ratio of $\mathrm{H}_{2} \mathrm{O} / \mathrm{H}_{2}$ and temperature, and that as the ratio of $\mathrm{H}_{2} \mathrm{O} / \mathrm{H}_{2}$ becomes high, the structure approaches to fayalite. The film consisting mostly of silica could not form except in the region of low ratio of $\mathrm{H}_{2} \mathrm{O} / \mathrm{H}_{2}$. The lower part of Table 5 shows the values of pressure ratio of $\mathrm{H}_{2} \mathrm{O} / \mathrm{H}_{2}$ at the temperatures, which were obtained postulating that the reactions written in the table are realized.

\section{Effect of Structure of Oxide Film on Decarburization Rate}

It is sure that amorphous silica formed on the surface is an obstacle that slows down the decarburization rate. As already known, however, the oxide film consists not only of amorphous silica, but also of fayalite. So the effect of structure of the oxide film on the decarburization rate has to be considered here. Figure 9 shows the results thus obtained. In the figure, the right scale of the ordinate shows the residual carbon content of steel which was obtained by chemical analysis, whereas the left scale shows the oxygen content. The film thickness can be readily calculated from this oxygen content, because in silicon steels with more than a certain silicon content, usually slightly less than $3 \%$ silicon, no internal oxidation can occur. The film thickness, however, was not calculated here and the oxygen content was left just as it was obtained.

It is obvious from the figure that for decreasing the decarburization rate amorphous silica is more influential than fayalite.

\section{Discussion}

Earlier studies ${ }^{3)}$ had shown that the decarburization of steels in hydrogen containing various amounts of water vapor and, as occasion demands, containing nitrogen occurs principally by the following reactions,

$$
\begin{array}{r}
\mathrm{C}+\mathrm{H}_{2} \mathrm{O}=\mathrm{CO}+\mathrm{H}_{2} \\
\mathrm{C}+2 \mathrm{H}_{2}=\mathrm{CH}_{4} \ldots
\end{array}
$$


Table 5. Crystal structure of oxide films of specimens heated in atmospheres with various amounts of water vapor at temperatures from $700^{\circ}$ to $1000^{\circ} \mathrm{C}$

\begin{tabular}{|c|c|c|}
\hline$p_{\mathrm{H}_{2} \mathrm{O}} / p_{\mathrm{H}_{2}}$ & $\begin{array}{l}\text { Temperature } \\
\left({ }^{\circ} \mathrm{C}\right)\end{array}$ & Crystal structure \\
\hline \multirow{3}{*}{0.024} & 800 & Amorphous \\
\hline & 900 & , \\
\hline & 1000 & ", \\
\hline \multirow{3}{*}{0.031} & 800 & Amorphous \\
\hline & 850 & , \\
\hline & 900 & $"$ \\
\hline \multirow{3}{*}{0.079} & 800 & Amorphous \\
\hline & 850 & , \\
\hline & 900 & , \\
\hline \multirow{3}{*}{0.105} & 800 & Amorphous \\
\hline & 850 & , \\
\hline & 900 & ” \\
\hline \multirow{4}{*}{0.157} & 800 & Amorphous \\
\hline & 850 & ’, \\
\hline & 900 & Amorphous + (fayalite) \\
\hline & 950 & Amorphous \\
\hline \multirow{4}{*}{0.262} & 800 & Amorphous \\
\hline & 850 & Amorphous + fayalite \\
\hline & 900 & Fayalite \\
\hline & 950 & , \\
\hline \multirow{4}{*}{0.326} & 800 & Amorphous + fayalite \\
\hline & 850 & Fayalite + amorphous \\
\hline & 900 & $"$ \\
\hline & 950 & Fayalite \\
\hline \multirow{4}{*}{0.523} & 800 & Fayalite \\
\hline & 850 & $"$ \\
\hline & 900 & , \\
\hline & 950 & , \\
\hline 0.11 & 800 & \multirow{3}{*}{$2 \mathrm{Fe}+\mathrm{SiO}_{2}+2 \mathrm{H}_{2} \mathrm{O}=\mathrm{Fe}_{2} \mathrm{SiO}_{4}+2 \mathrm{H}_{2}$} \\
\hline 0.17 & 900 & \\
\hline 0.23 & 1000 & \\
\hline 0.526 & 800 & $\mathrm{Fe}+\mathrm{H}_{2} \mathrm{O}=\mathrm{FeO}+\mathrm{H}_{2}$ \\
\hline
\end{tabular}

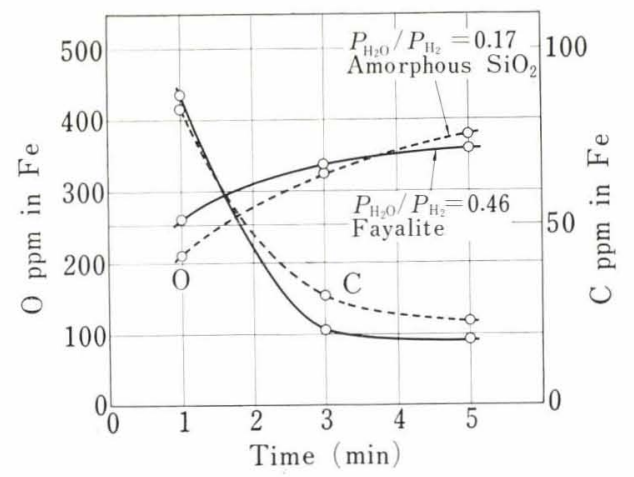

Fig. 9. Relation between carbon and oxygen content (ppm) in silicon steel and time

In this experiment using the mixtures of hydrogen and water vapor, the reaction (3) was predominant.
And, it was found that although the reaction (4) proceeds, the rate is relatively slow (Figs. 3 and 4). The present study on decarburization due to the reaction (3) showed that the decarburization rate increases with increasing water vapor content and temperature. However, it was found that the maximum water vapor content that can be added is limited, since, as the water vapor content exceeds a certain limit, the decarburization rate decreases. This phenomenon may be due to the oxide formation on the surface by the chemical reactions which is written as follows,

$$
\begin{array}{r}
\mathrm{Si}+2 \mathrm{H}_{2} \mathrm{O}=\mathrm{SiO}_{2}+2 \mathrm{H}_{2} \ldots \ldots \ldots \\
\mathrm{Fe}+\mathrm{H}_{2} \mathrm{O}=\mathrm{FeO}+\mathrm{H}_{2} \ldots \ldots \ldots \\
2 \mathrm{Fe}+\mathrm{SiO}_{2}+2 \mathrm{H}_{2} \mathrm{O}=\mathrm{Fe}_{2} \mathrm{SiO}_{4}+2 \mathrm{H}_{2}
\end{array}
$$

The effect of the oxides formed due to the reactions (5) and (6) on the decarburization has been well known. ${ }^{4)}$

From a thermodynamical consideration, the relation among the phases in equilibrium, oxygen partial pressure $\left(\mathrm{H}_{2} \mathrm{O} / \mathrm{H}_{2}\right)$, and temperature is obtained.

For the reaction (5),

$$
\left.\begin{array}{l}
2 \log \mathrm{H}_{2} \mathrm{O} / \mathrm{H}_{2}=-\Delta G^{\circ} / 4.575 T+\log a_{\mathrm{Si}} \\
\log f_{\mathrm{Si}}^{\mathrm{Fe}}=-4540 / T-0.549^{51} \\
\log a_{\mathrm{Si}}=\log (\mathrm{Si} \%)+\log f_{\mathrm{Si}}^{\mathrm{Fe}} \\
\Delta G^{\circ}=-90300+16.55 T \pm 3.16 \times 10^{3}{ }^{6)}
\end{array}\right\}
$$

Inserting the relationship (9) into the formula (8), the ratio of $\mathrm{H}_{2} \mathrm{O} / \mathrm{H}_{2}$ is obtained. Here, the silicon content of the steel used is $2.86 \%$, hence

$$
\log \mathrm{H}_{2} \mathrm{O} / \mathrm{H}_{2}=-7599 / \mathcal{T}+1.856
$$

For the reaction (6),

$$
\log \mathrm{H}_{2} \mathrm{O} / \mathrm{H}_{2}=-670 / T+0.34
$$

is obtained in the same way.

For the reaction (7),

$$
\log \mathrm{H}_{2} \mathrm{O} / \mathrm{H}_{2}=-1891 / \mathrm{T}+0.84 \ldots
$$

is obtained.

Summarization of these relationships is illustrated in Fig. 10. The figure also includes the following reaction.

$$
2 \mathrm{Fe}+\mathrm{Si}+4 \mathrm{H}_{2} \mathrm{O}=\mathrm{Fe}_{2} \mathrm{SiO}_{4}+4 \mathrm{H}_{2}
$$

Although having been expected to occur, the reaction (13) was not actually observed.

Comparing the equilibrium phases concerning the reactions (5) and (7) with the crystal structures obtained by electron diffraction, it was found that there was the consistency in these results, but for the formation of fayalite the reaction (7) occurs only in the region where temperatures are at or above $900^{\circ} \mathrm{C}$. At $800^{\circ} \mathrm{C}$, the formation of fayalite does not occur as far as the ratio of $\mathrm{H}_{2} \mathrm{O} / \mathrm{H}_{2}$ does not exceed 0.523 , which nearly corresponds to the ratio at which the reaction (6) occurs. As shown in Table 5, the ratio of $\mathrm{H}_{2} \mathrm{O} / \mathrm{H}_{2}$ at which the formation of fayalite actually occurs is 0.523 at $800^{\circ} \mathrm{C}$ and it is nearly equal to the ratio to 


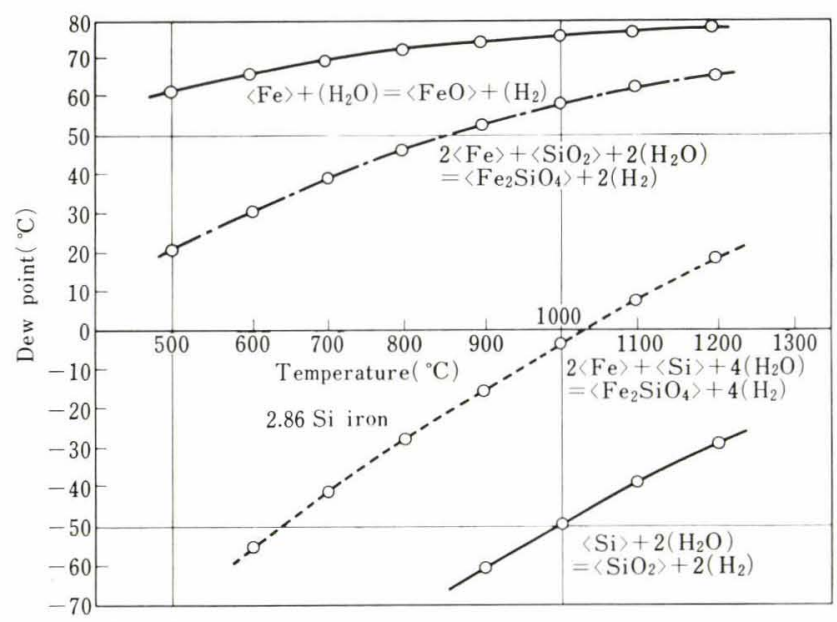

Fig. 10. Relation between oxygen partial pressure $\left(\mathrm{H}_{2} \mathrm{O} / \mathrm{H}_{2}\right)$ and temperature

form wustite, 0.526. When temperatures are low, the ratio of $\mathrm{H}_{2} \mathrm{O} / \mathrm{H}_{2}$ for the formation of fayalite necessitates much higher values than those obtained from the equilibrium of the reaction (7). It may be noted, therefore, that the region of silica obviously invades the region where fayalite is stable, although upper portion of the stable region of silica must be defined by the equilibrium relation of reaction (7).

The validity of the reason may be better understood from Table 4. Even the oxide film considered to consist of amorphous silica contains some amount of iron. Prolonging the heating time, the oxide film containing iron will change into fayalite in all or a part of the film.

Next, the effect of oxide films thus formed on the decarburization will be considered. For both of silica and fayalite, the rate of growth of the film increases with increasing temperature and ratio of $\mathrm{H}_{2} \mathrm{O} / \mathrm{H}_{2}$. Since the well grown oxide films have many faults, the thick oxide films do not grow very compact as the decarburization rate decreases. Especially, since the oxide film consisting of fayalite is nonprotective, this tendency will likely be large. On the contrary, the thin film is as compact as shown in the bright parts of Photo. 1 (a), so that it can act as a strong inhibitor for the decarburization. The evidence is illustrated better in Fig. 6.

Finally, the decarburization by solid state reaction will be considered. The reactions to be considered are as follows,

$$
\begin{aligned}
\mathrm{C}_{\mathrm{Si}-\mathrm{Fe}}+\mathrm{SiO}_{2} & =\mathrm{SiO}+\mathrm{CO} . \\
\mathrm{C}_{\mathrm{Si}-\mathrm{Fe}}+\mathrm{FeO} & =\mathrm{Fe}+\mathrm{CO} .
\end{aligned}
$$

For the reaction (14), the relation between the product of $P_{\mathrm{CO}} \cdot P_{\mathrm{SiO}}$ and the standard free energy is obtained as follows,

$$
\begin{gathered}
\log \left(P_{\mathrm{CO}} \cdot P_{\mathrm{SiO}}\right)=\log a_{\mathrm{C}}-\Delta G^{\circ} / 4.574 \mathrm{~T} \ldots \ldots \\
\Delta G^{\circ}=158300+8.44 T \log T-107.83 T .
\end{gathered}
$$

where $a_{\mathrm{C}}$ is the carbon activity in silicon steel, which was calculated by R. P. Smith ${ }^{7)}$ as 0.12 for the specimen of $2.86 \% \mathrm{Si}, 0.02 \% \mathrm{C}$ and at $1000^{\circ} \mathrm{C}$.
Inserting these values into the formula (16), the product of $P_{\mathrm{CO}} \cdot P_{\mathrm{SiO}}$ is obtained as follows,

$$
P_{\mathrm{CO}} \cdot P_{\mathrm{SiO}}=61.66 \times 10^{-12}
$$

Thus, it can be known that $P_{\mathrm{Co}}$ is of the order of $10^{-6}$.

Accordingly, the decarburization by solid state reaction is rather difficult to occur during an ordinary heat treatment, as $P_{\mathrm{Co}}$ may not be lower than the value of $7.8 \times 10^{-6} \mathrm{~atm}$. As seen in Figs. 3 and 4, the value of $P_{\mathrm{CO}}$ in equilibrium with silicon steel can never be lower than the value of $7.8 \times 10^{-6}$ atm even after a long period.

For the reaction (15), $P_{\mathrm{Co}}$ is $3.2 \times 10^{-3}$ at $1000^{\circ} \mathrm{C}$. Therefore, the decarburization is considered to occur. Considering that the dissociation pressure of $\mathrm{FeO}$ is high (the order of $10^{-7}$ at $1000^{\circ} \mathrm{C}$ ) and comparing with the oxygen partial pressure of hydrogen with various amounts of water vapor, $\mathrm{FeO}$ can not exist as a stable phase in this circumstance. Supposing that FeO exists, it readily reacts with silica and forms fayalite.

From discussion mentioned above, it is evident that the decarburization in hydrogen with various amounts of water vapor will be carried out by the reaction of silicon steels with gaseous atmospheres, principally water vapor, the decarburization of solid state reaction can hardly occur, and, moreover, that the effect of oxide films on the decarburization rate differs depending on the behavior of oxides formed in various conditions of temperature and ratio of $\mathrm{H}_{2} \mathrm{O} / \mathrm{H}_{2}$.

\section{Summary}

A study has been made on the decarburization of $3 \% \mathrm{Si}$ steels by means of gas-chromatography, electron diffraction, electron microprobe-analysis, and electron microscopy.

The decarburization of silicon steels heated in hydrogen with various amounts of water vapor, as occasion demands, with nitrogen at temperatures from $700^{\circ} \mathrm{C}$ through $1000^{\circ} \mathrm{C}$, occurs by the following reactions,

$$
\begin{aligned}
& \mathrm{C}_{\mathrm{Si}-\mathrm{Fe}}+\mathrm{H}_{2} \mathrm{O}=\mathrm{CO}+\mathrm{H}_{2} \ldots \\
& \mathrm{C}_{\mathrm{Si}-\mathrm{Fe}}+2 \mathrm{H}_{2}=\mathrm{CH}_{4} \ldots \ldots \ldots
\end{aligned}
$$

The principal reaction of decarburization is the reaction (a) as already known. The decarburization rate increases with increasing temperature and water vapor, but beyond some vapor pressure the increase in rate at $1000^{\circ} \mathrm{C}$ becomes small with further increase in the pressure. The limiting rate of decarburization may be considered due to oxidation of silicon in steels to form silica and also formation of fayalite.

The oxidation of silicon steels is carried out by the following reactions,

$$
\begin{aligned}
& \mathrm{Si}+2 \mathrm{H}_{2} \mathrm{O}=\mathrm{SiO}_{2}+2 \mathrm{H}_{2} \ldots \ldots \ldots \ldots \ldots \ldots \\
& 2 \mathrm{Fe}+\mathrm{SiO}_{2}+2 \mathrm{H}_{2} \mathrm{O}=\mathrm{Fe}_{2} \mathrm{SiO}_{4}+2 \mathrm{H}_{2} \\
& \mathrm{Fe}+\mathrm{H}_{2} \mathrm{O}=\mathrm{FeO}+\mathrm{H}_{2} \ldots \ldots \ldots \ldots \ldots \ldots \ldots \ldots \ldots \ldots \ldots
\end{aligned}
$$

It was confirmed by electron diffraction technique that these oxides exist in the conditions determined by 
thermodynamical calculation except for $\mathrm{Fe}_{2} \mathrm{SiO}_{4}$ at low temperatures. That is, the phase boundaries determined by thermodynamical calculations at temperatures from $700^{\circ}$ to $1000^{\circ} \mathrm{C}$ except for the reaction of fayalite formation at lower temperatures are much consistent with those determined by electron diffraction study.

Also was considered the effect of change of the crystal structures and of the appearance of oxide film during the formation upon the decarburization rate.

Finally, the decarburization by solid state reaction was considered difficult to occur.

\section{REFERENCES}

1) A. U. Seybolt and E. I. Olessandrini: Trans. AIME, 222 (1958), 507.

2) C. W. Tuck: Corros. Sci., 5 (1965), 631.

3) W. A. Pennigton: Trans. Amer. Soc. Metals, 37 (1946), 48. R. A. Hudson: Trans. AIME, 227 (1963), 695.

4) For example, S. H. Kalin: Flat Rolled Products III, (1962), 99, AIME, N.Y.

5) W. C. Leslie: Nitrogen in Ferritic Steels, (1959), 25, AIME, N.Y.

6) O. Kubachewski and E. LL. Evans: Metallurgical Thermochemistry, (1958), Pergamon Press, London.

7) R. P. Smith: J.Amer. Chem. Soc., 70 (1948), 2724. 